\title{
Kinetics of Phenol Oxidation in Supercritical Water
}

\author{
Thomas D. Thornton and Phillip E. Savage \\ Dept. of Chemical Engineering, University of Michigan, Ann Arbor, MI 48109
}

\begin{abstract}
Aqueous solutions of phenol were oxidized in a flow reactor at temperatures between 300 and $420^{\circ} \mathrm{C}\left(0.89 \leq T_{r} \leq 1.07\right)$ and pressures from 188 to 278 atm $\left(0.86 \leq P_{r} \leq 1.27\right)$. These conditions included oxidations in both near-critical and supercritical water. Reactor residence times ranged from 1.2 to $111 \mathrm{~s}$. The initial phenol concentrations were between 50 and $330 \mathrm{ppm}$ by mass, and the initial oxygen concentrations ranged from 0 to $1,100 \%$ excess. The oxidation experiments covered essentially the entire range of phenol conversions. Analysis of the kinetics data for phenol disappearance using a combination of the integral method and the method of excess revealed that the reaction was first order in phenol and $1 / 2$ order in oxygen, and influenced by pressure. The global reaction order for water was taken to be nonzero, and the global rate constant was assumed to be independent of pressure so that the only effect of pressure was to alter the water concentration and hence the reaction rate. This approach led to a global reaction rate law that was 0.7 order in water and had a rate constant with an activation energy of $12.4 \mathrm{kcal} / \mathrm{mol}$. The implications of these rate laws to the design of a commercial supercritical water oxidation reactor are also explored.
\end{abstract}

\section{Introduction}

Supercritical fluids have attracted attention as media in which to conduct chemical reactions because their physical and chemical properties can be altered, at times dramatically, through only modest changes in temperature or pressure. This extreme sensitivity to process variables affords opportunities to manipulate the reaction environment and possibly control the course of a reaction. Supercritical water (SCW), for instance, has emerged as a good solvent for the oxidative degradation of hazardous organic compounds. It is a good medium in which to oxidize organics because it provides a very high solubility for both organics (Connolly, 1966) and oxygen (Battino, 1981), and because the relatively high temperatures provide rapid oxidation rates.

Although SCW oxidation was patented relatively recently as a new technology for the ultimate destruction of organic wastes (Modell, 1982, 1985), it is very similar to the wellestablished technology of wet-air oxidation (Copa and Gitchel,

Correspondence concerning this article should be addressed to P. E. Savage.

Present address of T. D. Thornton: BP America, Warrensville Research and Environmental Science Center, Cleveland, OH 44128 .
1989; Zimmermann, 1961). Both processes involve the reaction of organics and oxygen in an aqueous phase to generate $\mathrm{CO}_{2}$ and $\mathrm{H}_{2} \mathrm{O}$ as the ultimate products. The key difference between wet-air oxidation and SCW oxidation is that the latter technology employs higher temperatures and pressures that exceed the critical properties of water. Operating at supercritical conditions leads to a homogeneous reaction mixture in which organics, water, and oxygen can exist in a single phase. This feature obviates the need for interphase oxygen transport, a step that often limited the rates of wet-air oxidation reactions. Additional operating and engineering advantages of SCW oxidation have been discussed in the literature (Modell, 1989; Thomason and Modell, 1984).

Because SCW oxidation is a relatively new technology, most of the previous research in this area had the demonstration of the efficacy of the technology as its focus (for example, Thomason and Modell, 1984; Modell, 1982, 1985; Staszak et al., 1987). There have been comparatively few studies of the kinetics of SCW oxidation reactions, and most of these have been for relatively simple compounds. Tester and coworkers, for instance, have reported global rate expressions for $\mathrm{CO}$ 
(Helling and Tester, 1987), $\mathrm{NH}_{3}$ and $\mathrm{C}_{2} \mathrm{H}_{5} \mathrm{OH}$ (Helling and Tester, 1988), $\mathrm{CH}_{3} \mathrm{OH}$ (Webley and Tester, 1989), $\mathrm{CH}_{4}$ (Webley and Tester, 1991), and $\mathrm{H}_{2}$ (Holgate and Tester, 1991). In addition, Rofer and Streit $(1988,1989)$ studied $\mathrm{CH}_{4}$ and $\mathrm{CH}_{3} \mathrm{OH}$ oxidation in SCW. In these studies, the reaction order for the organic compound was essentially unity, and the reaction order for oxygen was typically zero. It should be noted, however, that these reaction orders were assumed, rather than rigorously determined, in a few of these studies.

In one of the first studies involving SCW oxidation of compounds representative of actual organic pollutants, Wightman (1981) reported kinetics data for the oxidation of acetic acid, phenol and a large number of other compounds. By assuming that the reaction orders for the organic and for oxygen were both unity, and that $\mathrm{CO}_{2}$ was the exclusive carbon-containing product, Wightman (1981) was able to calculate rate constants and their activation energies. The validity of these assumptions was not verified, however, so the reliability of the quantitative kinetics results is an open question. Nevertheless, this work is significant because it demonstrated the broad applicability of SCW oxidation technology, and it provided qualitative information about the relative reactivities of a large number of different compounds.

In a more recent study involving a model organic pollutant, Yang and Eckert (1988) oxidized $p$-chlorophenol in near-critical and supercritical water in a plug-flow reactor. They examined the dependence of the average reaction rate (average rate $=\Delta[p$-chlorophenol $] / \tau)$ on the $p$-chlorophenol and oxygen concentrations, and reported that the reaction was first order in $p$-chlorophenol at low concentrations, second order at high concentrations, and always zero order in oxygen. Unfortunately, using an average reaction rate is not an accurate method of analysis for reaction kinetics from a plug-flow reactor unless conversions are low. Yang (1988) did not report the conversions for each experiment, but she did report that the maximum $p$-chlorophenol conversion was $95 \%$. If the conversions from many of the experiments were frequently high, then the rate constants reported by Yang (1988) and Yang and Eckert (1988) must be viewed as being only approximate.

The discussion above reveals that quantitative kinetics data for the SCW oxidation of representative organic pollutants are scarce and that the path to acquiring such data is fraught with potential pitfalls. Nevertheless, such kinetics data are useful for engineering design and economic evaluation of SCW oxidation processes. In this article, we report the results of a study of the kinetics of phenol oxidation in SCW.

\section{Experimental Studies}

Phenol was oxidized at temperatures between 300 and $420^{\circ} \mathrm{C}$, and pressures from 188 to $278 \mathrm{~atm}$. Reactor residence times ranged from 1.2 to $111 \mathrm{~s}$. The resulting phenol conversions ranged from less than $1 \%$ to greater than $99 \%$. The initial phenol concentrations were between 50 and 330 parts per million by mass ( $\mathrm{ppm})$, which resulted in concentrations between $1.7 \times 10^{-4}$ and $2.1 \times 10^{-3} \mathrm{M}$ at reaction conditions. The initial oxygen concentrations ranged from $0 \%$ excess (the precise stoichiometric amount needed to convert phenol to $\mathrm{CO}_{2}$ and $\mathrm{H}_{2} \mathrm{O}$ ) to $1,100 \%$ excess, which resulted in oxygen concentrations between $6.5 \times 10^{-3}$ and $5.6 \times 10^{-2} \mathrm{M}$ at reaction conditions. These phenol and oxygen concentrations were calculated by assuming that the density of the reaction mixture was the same as that of water. This assumption is good because the reaction mixture was typically greater than $99 \%$ water. Using low reactant concentrations also ensured that a single phase existed at all reaction conditions and that the maximum adiabatic temperature rise would be limited to less than $1^{\circ} \mathrm{C}$.

Phenol oxidation experiments were conducted in an isothermal, isobaric flow reactor fashioned from 1/8-in. (3.2$\mathrm{mm})$ OD Hastelloy C-276 tubing. The reactor operation approximated plug-flow behavior as evidenced by meeting the criteria of Cutler et al. (1988). The reactor feed streams were prepared by dissolving oxygen into deionized water in onefeed tank and loading a previously prepared aqueous solution of phenol into a second-feed tank. Helium blanketed the headspace of the phenol-water feed tank so that no oxygen entered the reactor through this feed stream. High-pressure metering pumps with a nominal flow rate range of $0.1-10 \mathrm{~mL} / \mathrm{min}$ were used to pressurize the two-feed streams. The two streams were then separately preheated by flowing through $1 / 16$-in. (1.6-mm) OD Hastelloy tubing immersed in a preheated, temperature-controlled, isothermal fluidized sand bath. In addition to the phenol oxidation experiments, we did separate phenol pyrolysis experiments in SCW to verify that none of the phenol would react in this preheater line.

The preheated feed streams were mixed at the reactor inlet using a specially machined Hastelloy mixing tee, and the reaction temperature was measured via a thermocouple placed within this mixing tee. After passing through the reactor, the mixture was cooled rapidly by passing through a tube-in-tube heat exchanger with cooling water in the annulus. After passing through back-pressure regulators to reduce the system pressure, the product stream was separated into liquid and vapor phases. The liquid product was collected in a graduated cylinder, and its flow rate was determined by measuring the time required for the volume to change by some specified amount.

The concentration of phenol in the reactor effluent was determined by reverse-phase, high-performance liquid chromatography using a UV detector. Deionized water flowing at $3.0 \mathrm{~mL} / \mathrm{min}$ served as the mobile phase, and a C-18 bondedphase column served as the stationary phase. Additional details about these analyses and the experimental procedure have been reported previously (Thornton and Savage, 1990). This earlier report also showed that the effects of homogeneous metalcatalyzed reactions were probably insignificant, because the concentration of metals (corrosion products) in the reactor effluent was very low. The effects of any heterogeneous metalcatalyzed reactions were also minimal, because altering the reactor surface to volume ratio did not alter the measured conversion (Thornton, 1991).

\section{Reaction Kinetics}

The objectives of our kinetics analysis were to determine the reaction rate constant $(k)$, its associated Arrhenius parameters, and the reaction orders for phenol $(a)$, oxygen $(b)$, and water (c) for the power-law rate expression in Eq. 1:

$$
\text { Rate }=k[\text { Phenol }]^{a}\left[\mathrm{O}_{2}\right]^{b}\left[\mathrm{H}_{2} \mathrm{O}\right]^{c}
$$

The specific volume of the reaction mixture was essentially constant because the reactions were accomplished in an iso- 
baric, isothermal, plug-flow reactor. By combining the design equation for this type of reactor (Fogler, 1992) with the powerlaw rate expression of Eq. 1 and noting that the concentration of phenol can be written in terms of its initial concentration and the conversion $(X)$, we obtain:

$$
\frac{d X}{d \tau}=k[\text { Phenol }]_{o}^{a-1}(1-X)^{a}\left[\mathrm{O}_{2}\right]^{b}\left[\mathrm{H}_{2} \mathrm{O}\right]^{c}
$$

The mole fraction of water exceeded 0.99 in nearly all of the experiments, so the concentration of water did not change appreciably during the reaction. Thus, we take the quantity $\left[\mathrm{H}_{2} \mathrm{O}\right]^{c}$ to be conversion invariant. Additionally, all of the data used in the kinetics analysis were obtained from experiments that were conducted with a large excess of oxygen ( $>200 \%$ excess in all cases) so that the concentration of oxygen could be approximated as being roughly equal to its initial concentration. Thus, the term $\left[\mathrm{O}_{2}\right]^{b}$ can be taken to be conversion invariant and approximately equal to $\left[\mathrm{O}_{2}\right]_{0}^{b}$.

Note that working with excess oxygen is required because it is impossible to determine a priori a stoichiometric relationship between phenol disappearance and oxygen consumption. This is because the overall reaction

$$
\mathrm{C}_{6} \mathrm{H}_{5} \mathrm{OH}+7 \mathrm{O}_{2} \rightarrow 6 \mathrm{CO}_{2}+3 \mathrm{H}_{2} \mathrm{O}
$$

does not proceed in a single step. Rather, there are numerous intermediate reaction products (Thornton and Savage, 1990; Thornton et al., 1991) so that a more accurate, but still greatly simplified, description of the reaction would be:

$$
\mathrm{C}_{6} \mathrm{H}_{5} \mathrm{OH} \stackrel{+r \mathrm{O}_{2}}{\longrightarrow} \text { Intermediate Products } \stackrel{+s \mathrm{O}_{2}}{\longrightarrow} 6 \mathrm{CO}_{2}+3 \mathrm{H}_{2} \mathrm{O}
$$

where $r$ and $s$ are stoichiometric coefficients with unspecified values. Thus, the presence of these intermediates and the multiple reaction pathways renders invalid the simple stoichiometric relation $\left[\mathrm{O}_{2}\right]=\left[\mathrm{O}_{2}\right]_{o}-7 X[\text { Phenol }]_{o}$, which describes the overall reaction.

With the oxygen and water concentrations being conversion invariant, Eq. 2 becomes a separable differential equation that can be solved as:

$$
f(X)=\int_{0}^{X} \frac{d X}{(1-X)^{a}}=k \tau[\text { Phenol }]_{o}^{a-1}\left[\mathrm{O}_{2}\right]_{o}^{b}\left[\mathrm{H}_{2} \mathrm{O}\right]^{c}
$$

This equation forms the basis for our kinetics analysis.

\section{Phenol reaction order}

To determine the reaction order with respect to phenol, we measured the phenol conversions obtained at different reactor residence times for reactions run at the same temperature, pressure and initial concentrations of the reactants. We then carried out the integration indicated in Eq. 5 for different integer and half-integer values for the phenol reaction order and plotted the data as $f(X)$ vs. $\tau$. The value of $a$ that resulted in a linear plot was selected as the phenol reaction order.

Figure 1 displays this integral method plot for a rate law that is first order in phenol $(a=1)$. These data were obtained from reactions at $380^{\circ} \mathrm{C}$ and $278 \mathrm{~atm}$, and using a 100-ppm

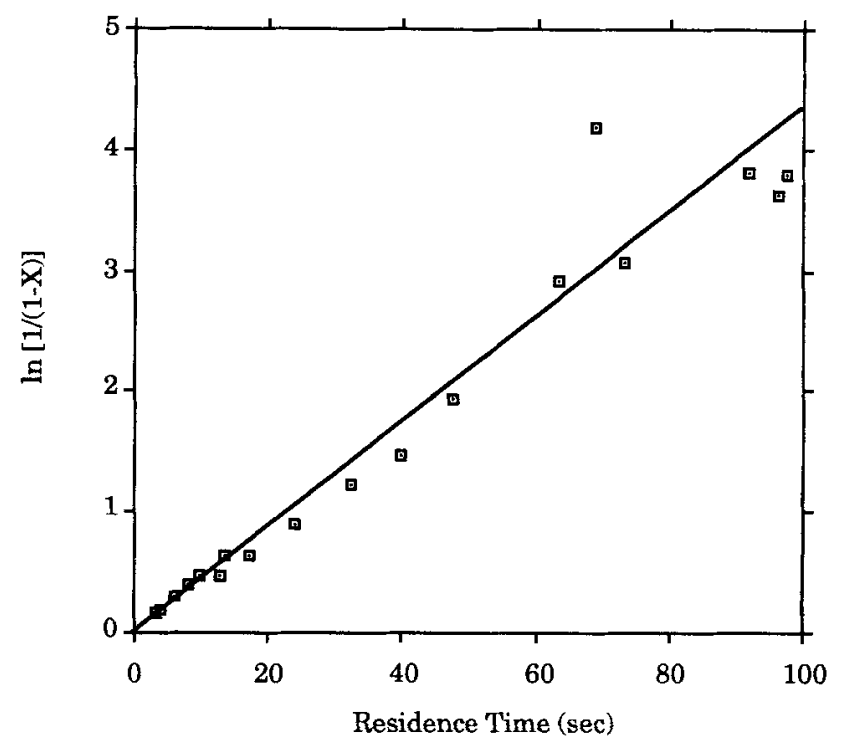

Figure 1. Integral method analysis for determining the phenol reaction order $\left(380^{\circ} \mathrm{C}, 278 \mathrm{~atm}, 100\right.$ ppm phenol, $800 \%$ excess oxygen).

initial phenol concentration and $800 \%$ excess oxygen. The phenol conversions ranged from 15 to $98 \%$. We intentionally conducted several runs at long residence times to obtain high phenol conversions because the integral method of kinetics analysis is most discriminating between rival rate laws when high-conversion data are available. These experimental data, when plotted as $f(X)=\ln [1 /(1-X)]$ vs. $\tau$, are clearly linear. Likewise, data collected from oxidation experiments at other sets of reaction conditions were also consistent with a global reaction rate law that was first order in phenol. Thus, we conclude that under the experimental conditions studied here, phenol oxidation in supercritical water is first order in phenol.

\section{Oxygen reaction order}

Most previous studies of the kinetics of oxidation in supercritical water determined the oxygen reaction order to be zero (Helling and Tester, 1987; Yang and Eckert, 1988; Webley and Tester, 1989). Thus, we first sought to determine whether there was any influence of the oxygen concentration on the kinetics of phenol oxidation in supercritical water. We conducted three sets of experiments in which all process variables, except for the oxygen concentration, were held constant. These experiments were all accomplished at $380^{\circ} \mathrm{C}$ and $278 \mathrm{~atm}$ with a 250 -ppm initial phenol concentration $\left(1.3 \times 10^{-3} \mathrm{M}\right)$. The three different initial oxygen concentrations were $1.1 \times 10^{-2}$, $3.1 \times 10^{-2}$ and $5.0 \times 10^{-2} \mathrm{M}$, which corresponded to approximately 0,250 and $450 \%$ excess oxygen.

Figure 2 displays the results of these experiments in terms of the phenol conversions achieved at different residence times for each of the three different oxygen levels. Figure 2 shows that the phenol conversions were higher in the experiments with the higher oxygen concentrations. For example, at a residence time of $32 \mathrm{~s}$, the conversion increased from $45 \%$ to $75 \%$, when the oxygen concentration increased from 0 to $450 \%$ excess. Thus, the reaction order for oxygen must be greater than zero for phenol oxidation in supercritical water. 


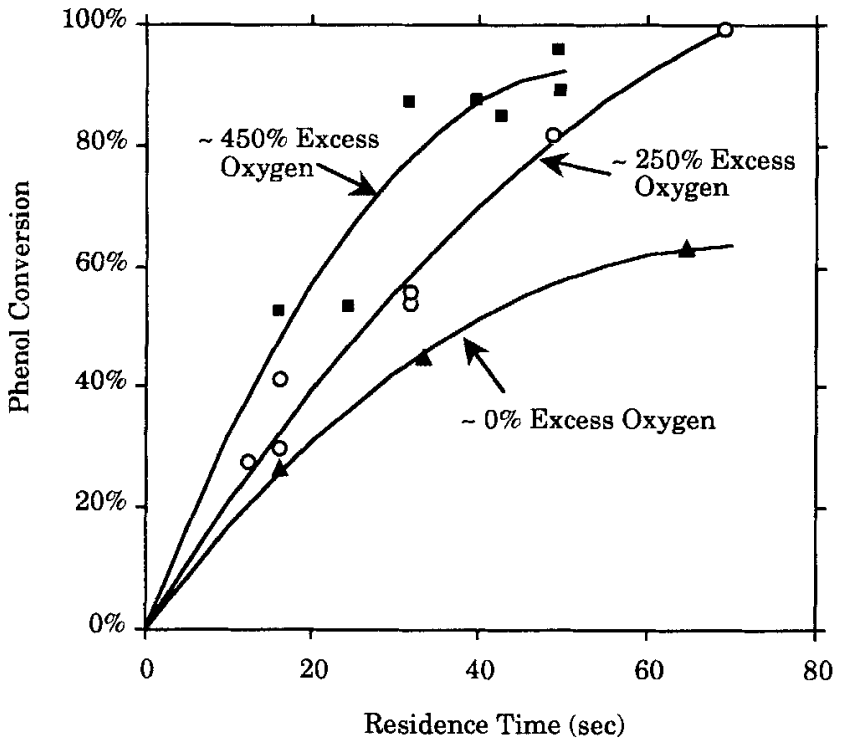

Figure 2. Effect of different oxygen concentrations on phenol conversion $\left(380^{\circ} \mathrm{C}, 278 \mathrm{~atm}, 250 \mathrm{ppm}\right.$ phenol).

To determine a numerical estimate for the oxygen reaction order, we first conducted experiments at $380^{\circ} \mathrm{C}$ and 278 atm using six different oxygen concentrations that ranged from $8.7 \times 10^{-3}$ to $5.1 \times 10^{-2}$ M. Plotting the data as $f(X)=$ $\ln [1 /(1-X)]$ vs. $r$ for each of the different oxygen concentrations gave straight lines, and according to Eq. 5 the slopes of these lines were equal to $k\left[\mathrm{O}_{2}\right]_{o}^{b}\left[\mathrm{H}_{2} \mathrm{O}\right]^{\mathrm{c}}$. Therefore, plotting the values of these slopes as a function of the initial oxygen concentration used in each set of experiments on log-log coordinates should give a straight line with slope equal to $b$, the oxygen reaction order. Figure 3 displays our data plotted in this form. The slope of the line that best describes these data leads to a global reaction rate law that is $1 / 2$ order in oxygen.

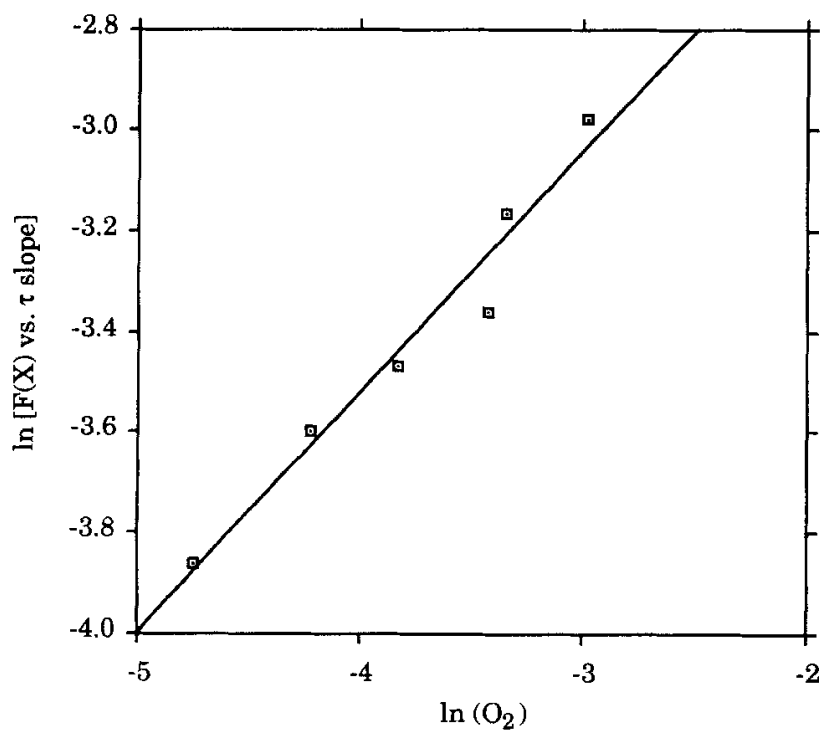

Figure 3. Oxygen reaction-order determination $\left(380^{\circ} \mathrm{C}\right.$, $278 \mathrm{~atm})$.

\section{Effect of pressure}

One means whereby pressure can influence the kinetics of phenol oxidation is that the reaction order with respect to water is nonzero and that changes in pressure change the water concentration and hence the reaction rate. The water reaction order being nonzero implies that water is a participant in the oxidation reactions. This notion is consistent with the literature dealing with reactions in SCW. Helling and Tester (1987), for instance, noted that the water-gas shift reaction was operative during CO oxidation in SCW. Rofer and Streit $(1988,1989)$ included elementary reaction steps that involved water as a reactant in their detailed kinetic models of methane oxidation in SCW. Additionally, several pyrolysis studies in SCW revealed that water was an active participant in the reaction and not merely an inert solvent (Lawson and Klein, 1985; Townsend and Klein, 1985; Townsend et al., 1988; Huppert et al., 1989; Houser et al., 1986).

To determine the reaction order for water for phenol oxidation in SCW, we first noted that the phenol reaction order was unity and the oxygen reaction order was 0.5 , so that Eq. 5 can be rearranged as:

$$
k\left[\mathrm{H}_{2} \mathrm{O}\right]^{c}=\frac{1}{\tau\left[\mathrm{O}_{2}\right]_{o}^{0.5}} \ln \left(\frac{1}{1-X}\right)
$$

We then used the results from 70 experiments conducted at $380^{\circ} \mathrm{C}$ and pressures of $188,218,233$ and 278 atm to calculate values for the quantity $k\left[\mathrm{H}_{2} \mathrm{O}\right]^{c}$ at each of these four different pressures using Eq. 6. Under these experimental conditions, the water concentration varied from 6.0 to $28.6 \mathrm{M}$. Determining values of $k\left[\mathrm{H}_{2} \mathrm{O}\right]^{c}$, which we term $k^{\prime}$, at each of the four different pressures (and hence four different water concentrations) allowed the water reaction order to be determined from a log-log plot of $k^{\prime}$ vs. $\left[\mathrm{H}_{2} \mathrm{O}\right]$.

The results of this analysis are displayed in Figure 4, where the error bars denote $95 \%$ confidence intervals. The error bars are large because these data were obtained at $380^{\circ} \mathrm{C}$, which is very near the critical temperature, where even a small uncer-

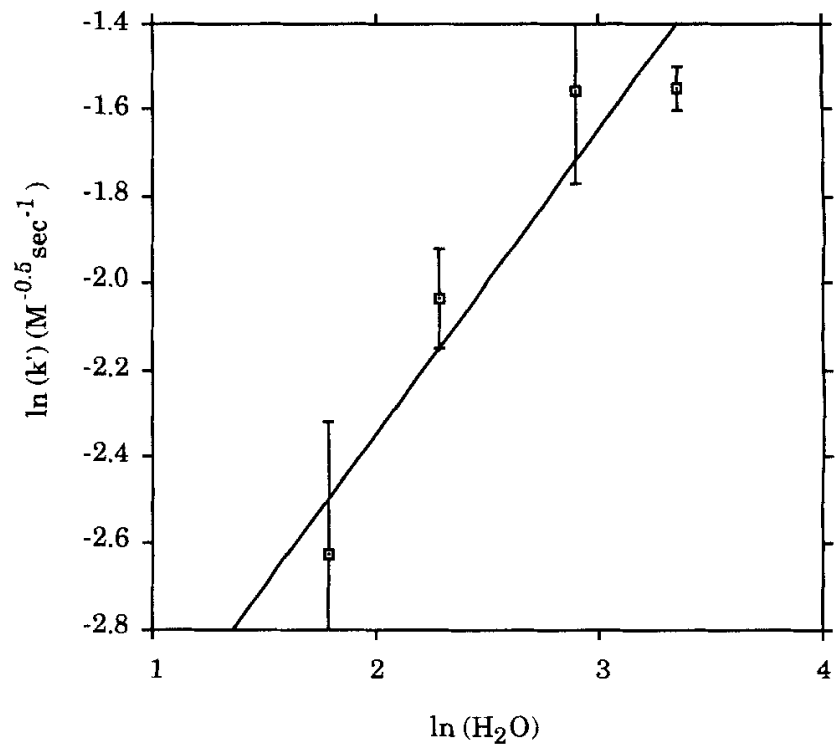

Figure 4. Water reaction-order determination $\left(380^{\circ} \mathrm{C}\right)$. 
tainty in temperature or pressure can lead to a large uncertainty in density. Linear regression of the four points in Figure 4 results in a slope of 0.7 , which is equal to the water reaction order.

The analysis in Figure 4 is based on the assumption that the pressure had no effect on the reaction rate constant and that the only effect of pressure was to change the water density. Note, however, that transition state theory indicates that rate constants for elementary reaction steps can be pressure-dependent. The variation of the rate constant with pressure is given by:

$$
\left.\left(\frac{\partial \ln k_{x}}{\partial P}\right)\right|_{T}=\frac{-\Delta V_{+}^{\ddagger}}{R T}
$$

where $\Delta V \ddagger$ is the activation volume. This parameter represents the difference in the partial molar volumes of the activated complex and the reactants.

Undoubtedly, a large number of individual elementary reaction steps contribute to the overall reaction for phenol oxidation in SCW. Thus, the global rate constant may possess a pressure dependence, and a value for a global activation volume could be determined (Thornton, 1991). Note, however, that it would be difficult to attach any theoretical or mechanistic significance to the value of the global activation volume, because numerous elementary steps contribute to the overall reaction. Therefore, in the kinetics analysis presented here, we will neglect potential pressure effects on the global rate constant and rather consider the only effect of pressure to be its influence on the water density.

\section{Effect of temperature}

Having determined the reaction orders for a global rate law for phenol disappearance at $380^{\circ} \mathrm{C}$ and pressures of 188,218 , 233 and $278 \mathrm{~atm}$, we next sought to determine the Arrhenius parameters. Thus, we conducted additional experiments at 300 , 340,400 and $420^{\circ} \mathrm{C}$ and $278 \mathrm{~atm}$, and at $400^{\circ} \mathrm{C}$ and $248 \mathrm{~atm}$. Within this range of conditions, water exists in a liquid-like $\left(T_{r}<1, P_{r}>1\right)$, a vapor-like $\left(T_{r}>1, P_{r}<1\right)$, and a supercritical fluid phase $\left(T_{r}>1, P_{r}>1\right)$, but because we used relatively dilute concentrations of oxygen and phenol, a single phase was always present in the reactor. We determined the values of the reaction rate constants at each temperature and pressure, and these rate constants are displayed on the Arrhenius plot of Figure 5. Each point on this plot corresponds to a rate constant determined from a set of experiments conducted at the same temperature and pressure. Linear regression of the data in Figure 5 leads to an activation energy of 12.4 $\mathrm{kcal} / \mathrm{mol}$.

This value for $E_{a}$ is in the same range as those previously reported from studies of wet oxidation and supercritical water oxidation of phenol. Pruden and coworkers $(1973,1976)$, for instance, oxidized phenol at temperatures between 200 and $250^{\circ} \mathrm{C}$ and pressures from 55 to $150 \mathrm{~atm}$. They reported an activation energy of $10.8 \mathrm{kcal} / \mathrm{mol}$ for phenol oxidation. Helling et al. (1981) also oxidized phenol under wet-air oxidation conditions, but they found the activation energy to be $4.9 \mathrm{kcal} /$ mol. Finally, Wightman (1981) oxidized phenol under SCW oxidation conditions, and he reported an activation energy of $15.2 \mathrm{kcal} / \mathrm{mol}$ for phenol destruction.

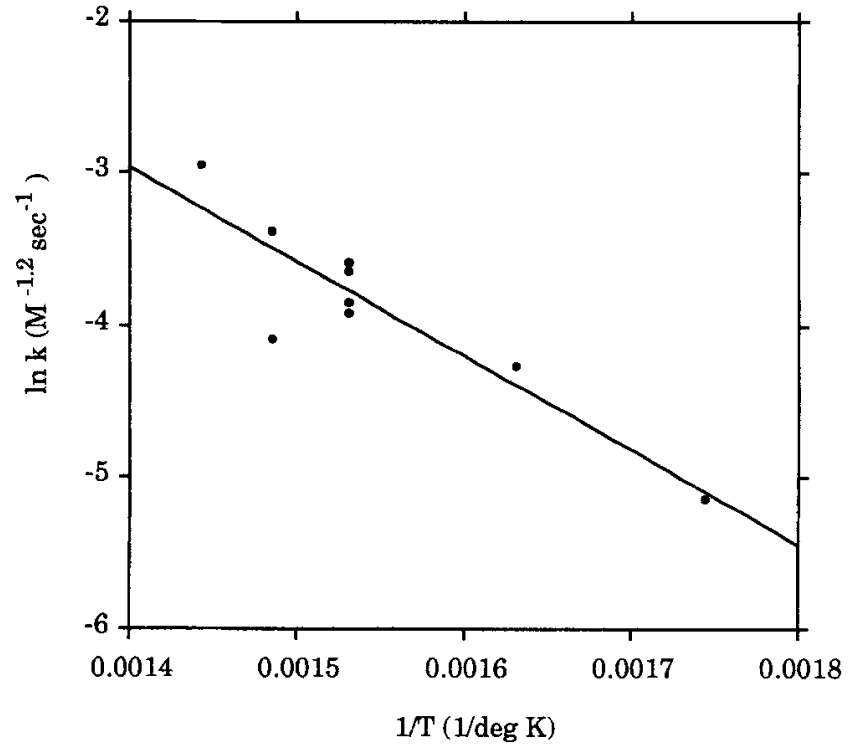

Figure 5. Arrhenius plot for phenol oxidation.

\section{Summary}

The kinetics analysis presented in this work has led to a global rate expression that describes the disappearance of phenol during SCW oxidation. This rate law is given as:

$$
\text { Rate }=k[\text { Phenol }]^{1.0}\left[\mathrm{O}_{2}\right]_{o}^{0.5}\left[\mathrm{H}_{2} \mathrm{O}\right]^{0.7}
$$

The rate constant is taken to be pressure invariant and a function of temperature only with Arrhenius parameters of $A=303 \mathrm{M}^{-1.2} \cdot \mathrm{s}^{-1}$ and $E_{a}=12.4 \mathrm{kcal} / \mathrm{mol}$. Figure 6, which compares the experimental phenol conversions with the conversions calculated from Eq. 2 using the rate law of Eq. 8, demonstrates that this rate law provides a good correlation of the experimental data.

Equation 8 describes the kinetics of phenol disappearance

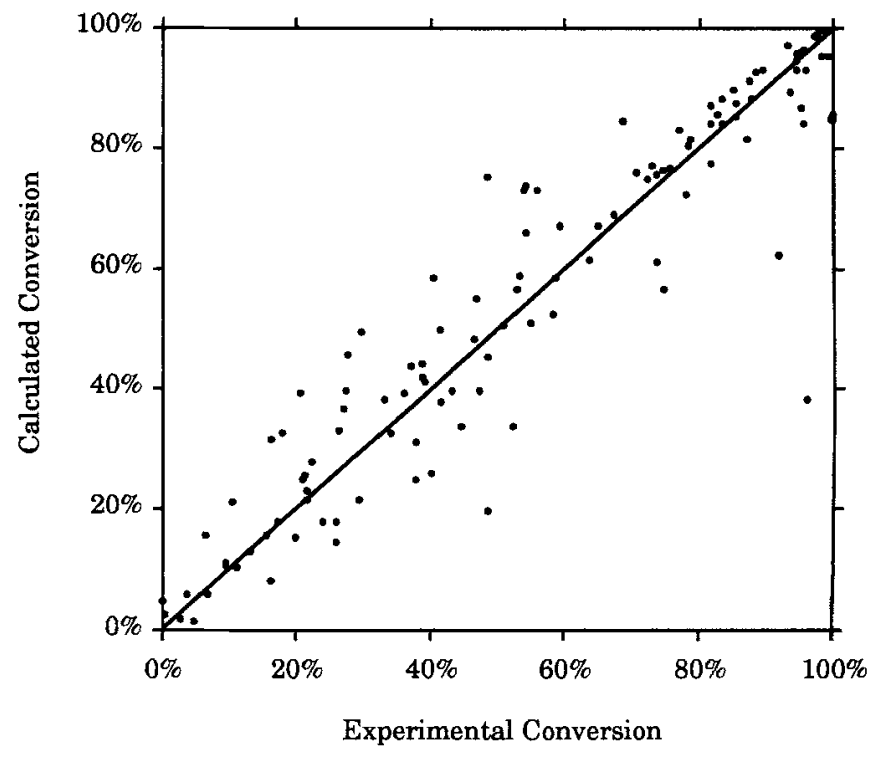

Figure 6. Comparison of experimental and calculated phenol conversions. 
at temperatures between 300 and $420^{\circ} \mathrm{C}$ and pressures between 188 and 278 atm, a wide range of conditions under which water can exist in a liquid-like, vapor-like or supercritical fluid phase. Thus, the rate expression can estimate the oxidation kinetics for fluid phases with different densities. The correlation is limited, however, to conditions where a single phase is present in the reactor, a condition that was met in all of the experimental work reported here.

\section{Implications to Commercial Processes}

To ensure the most favorable economics for the SCW oxidation process, it is desirable to achieve high destruction and removal efficiencies (DRE) using the minimum reactor volume (or shortest residence time) because the reactor can account for a significant fraction (50\%) of the total equipment cost (Eckert et al., 1990). The rate expression for phenol destruction reported in the previous section then has implications to SCW oxidation processes, because it can be used to explore the effects of temperature and pressure on the residence times required to achieve a desired DRE. We will, of course, limit this exploration to the range of temperatures $\left(300-420^{\circ} \mathrm{C}\right)$ and pressures (188-278 atm) investigated experimentally. We will use $99.99 \%$ as the desired DRE in the analysis that follows, because among the many regulations and standards that apply to the thermal treatment of hazardous waste, a $99.99 \%$ DRE for each principal organic hazardous constituent (POHC) present in the waste stream is frequently cited (U.S. EPA, 1986). Additionally, we will consider a single-phase feed stream that contains $1,000 \mathrm{ppm}$ phenol and $200 \%$ excess oxygen.

Figure 7, which displays the results of the analysis, shows the residence times required for a $99.99 \%$ DRE of phenol as a function of temperature at two different pressures. Minima are clearly present for each of the pressures. At $188 \mathrm{~atm}$, for example, a temperature of $360^{\circ} \mathrm{C}$ results in a minimum residence time of $147 \mathrm{~s}$. Increasing the temperature just 10 degrees beyond $360^{\circ} \mathrm{C}$, however, leads to a dramatic increase in the

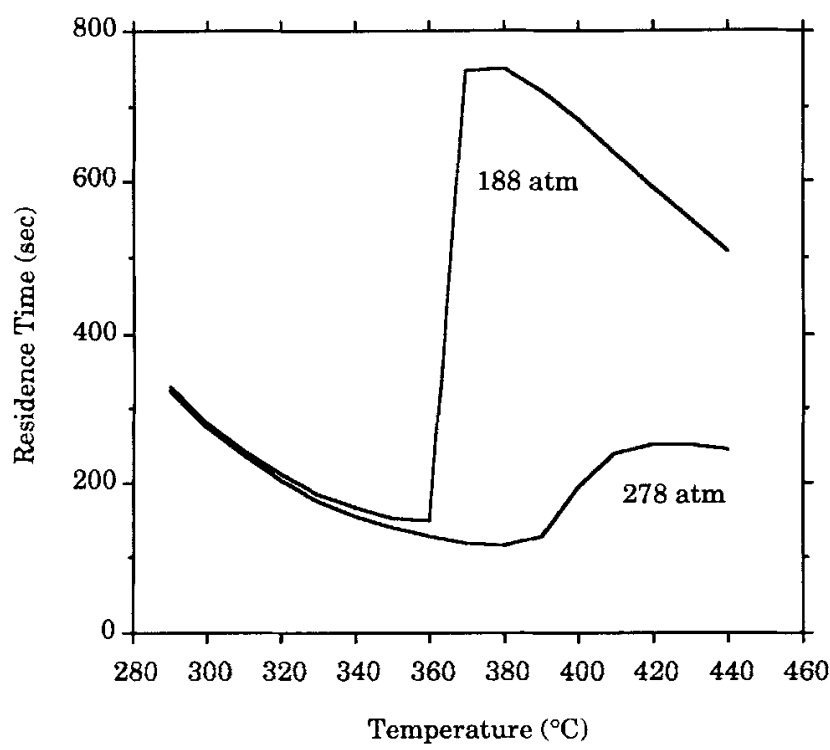

Figure 7. Effects of temperature and pressure on residence times required for $99.99 \%$ DRE of phenol. required residence time to $746 \mathrm{~s}$. Further increases in temperature cause the required residence time to decrease. This type of effect of temperature was observed in the experimental work (Thornton, 1991).

The existence of these minima and of a region where the residence time increases as the temperature increases are attributable to the competing effects of temperature on the reaction rate constant and on the reactant concentrations. Increasing the temperature increases the reaction rate constant exponentially, but it also decreases the reaction density and hence the concentrations of the reactants. Throughout most of the parameter space, the rate constant increases more rapidly than the density decreases, so the required residence times decrease. Near the critical point of water $\left(T_{c}=374^{\circ} \mathrm{C}, P_{c}=\right.$ $218 \mathrm{~atm}$ ), however, the density decrease overwhelms the rate constant increase so the required residence time increases. This increase is less dramatic at 278 atm than it is at 188 atm because the effect of temperature on the reaction density is less pronounced at this higher pressure. At temperatures well above the critical temperature, the residence times again begin to decrease as the temperature increases. Thus, the key implication of these results to applications of SCW oxidation technology is that short residence times can achieve high DREs even below the critical point of water because the reaction density is high. Much higher temperatures would be required to compensate for the lower densities at supercritical conditions.

Keep in mind that the results in Figure 7 are for the specific case of the oxidation of a relatively dilute stream of phenol in SCW. Results for other streams in which two or more phases may be present at subcritical conditions may be different because of the potential significance of interphase transport limitations on the oxidation kinetics. Note also that this section considered only the effects of temperature and pressure on the DRE of the POHC. Other issues (such as corrosion, formation of partial oxidation products, and formation of potentially hazardous products) would also have to be considered in the design and optimization of a commercial SCW oxidation process.

\section{Acknowledgment}

We thank Doug LaDue for experimental assistance. This project was partially supported by the National Science Foundation (CTS8906860 and CTS-9015738) and the Shell Faculty Career Initiation Fund.

\section{Notation}

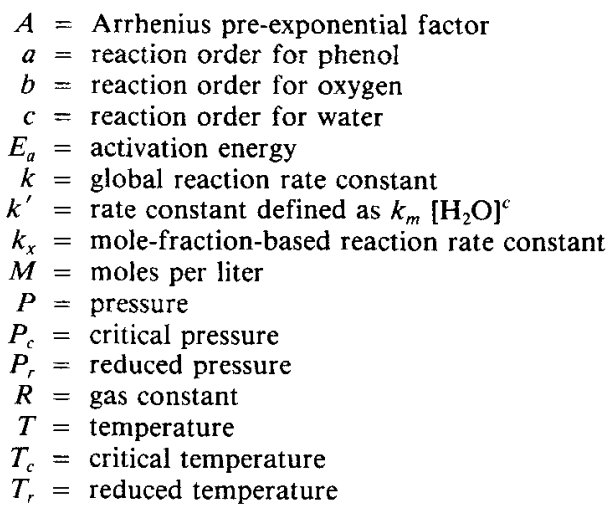


$\Delta \boldsymbol{V}_{\ddagger}^{\ddagger}=$ activation volume

$X=$ phenol conversion

\section{Greek letters}

$\tau=$ residence time

\section{Literature Cited}

Battino, R., ed., Solubility Data Series, Vol. 7, Oxygen and Ozone, Pergamon Press, New York (1981).

Connolly, J. F., "Solubility of Hydrocarbons in Water Near the Critical Solution Temperatures," J. Chem. Eng. Data, 11, 13 (1966).

Copa, W. M., and W. B. Gitchel, "Wet Oxidation," Standard Handbook of Hazardous Waste Treatment and Disposal, H. M. Freeman, eds., Sec. 8.6, McGraw-Hill, New York (1989).

Cutler, A. H., M. J. Antal, and M. Jones, "A Critical Evaluation of the Plug-Flow Idealization of Tubular-Flow Reactor Data," Ind. Eng. Chem. Res., 27, 691 (1988).

Eckert, C. A., G. W. Leman, and H. H. Yang, "Homogeneous Catalysis for Wet Oxidation: Design and Economic Feasibility of a Mobile Detoxification Unit," Haz. Mat. Control, 3, 20 (1990).

Fogler, H. S., Elements of Chemical Reaction Engineering, PrenticeHall (1992).

Helling, R. K., M. K. Strobel, and R. J. Torres, "Kinetics of Wet Oxidation of Biological Sludges from Coal Conversion Wastewater Treatment," ORNL/MIT-332 (1981).

Helling, R. K., and J. W. Tester, "Oxidation Kinetics of Carbon Monoxide in Supercritical Water," Energy \& Fuels, 1, 417 (1987).

Helling, R. K. and J. W. Tester, "Oxidation of Simple Compounds and Mixtures in Supercritical Water: Carbon Monoxide, Ammonia, and Ethanol," Env. Sci. Tech., 22, 1319 (1988).

Holgate, H. R., and J. W. Tester, "Fundamental Kinetics and Mechanisms of Hydrogen Oxidation in Supercritical Water," Proc. Int. Conf. Supercritical Fluids, 177 (1991).

Houser, T. J., D. M. Tiffany, Z. Li, and E. McCarville, M. E. Houghton, "Reactivity of Some Organic Compounds with Supercritical Water," Fuel, 65, 827 (1986).

Huppert, G. L., B. C. Wu, S. H. Townsend, M. T. Klein, and S. C. Paspek, "Hydrolysis in Supercritical Water: Identification and Implications of a Polar Transition State,"'Ind. Eng. Chem. Res., 28, 161 (1989).

Lawson, J. R., and M. T. Klein, "Influence of Water on Guaiacol Pyrolysis," Ind. Eng. Chem. Fundam., 24, 203 (1985).

Modell, M., "Supercritical-Water Oxidation," Standard Handbook of Hazardous Waste Treatment and Disposal, H. M. Freeman, ed., Sec. 8.11, McGraw-Hill, New York (1989).

Modell, M. "Processing Methods for the Oxidation of Organics in Supercritical Water," U.S. Patent No. 4,338,199 (July 6, 1982).

Modell, M., "Processing Methods for the Oxidation of Organics in Supercritical Water,"' U.S. Patent No. 4,543,190 (Sept. 24, 1985).

Pruden, B. B., and D. R. Ferguson, "Removal of Phenol in Waste
Water by Wet Air Oxidation," Water Poll. Res. Canada, 8, 148 (1973).

Pruden, B. B., and H. Le, "Wet Air Oxidation of Soluble Components in Waste Water," Can. J. Chem. Eng., 54, 319 (1976).

Rofer, C. K., and G. E. Streit, "Kinetics and Mechanism of Methane Oxidation in Supercritical Water," Los Alamos National Laboratory Report LA-11439-MS DOE/HWP-64 (1988).

Rofer, C. K., and G. E. Streit, "Oxidation of Hydrocarbons and Oxygenates in Supercritical Water," Los Alamos National Laboratory Report LA-11700-MS DOE/HWP-90 (1989).

Staszak, C. N., K. C. Malinowski, and W. R. Killilea, "The Pilot Scale Demonstration of the MODAR Oxidation Process for the Destruction of Hazardous Organic Waste Materials," Env. Prog., 6, 39 (1987).

Thomason, T. B, and M. Modell, "Supercritical Water Destruction of Aqueous Wastes," Hazard. Waste, 1, 453 (1984).

Thornton, T. D., "Phenol Oxidation in Supercritical Water: Reaction Kinetics, Products, and Pathways," PhD Thesis, Univ. of Michigan, Ann Arbor (1991).

Thornton, T. D., and P. E. Savage, "Phenol Oxidation in Supercritical Water," J. Supercritical Fluids, 3, 240 (1990).

Thornton, T. D., D. E. LaDue, and P. E. Savage, "Phenol Oxidation in Supercritical Water: Formation of Dibenzofuran, Dibenzop-dioxin, and Related Compounds," Environ. Sci. Technol., 25, 1507 (1991).

Townsend, S. H., and M. T. Klein, "Dibenzyl Ether as a Probe into the Supercritical Fluid Solvent Extraction of Volatiles from Coal with Water," Fuel, 64, 635 (1985).

Townsend, S. H., M. A. Abraham, G. L. Huppert, M. T. Klein, and S. C. Paspek, "Solvent Effects during Reactions in Supercritical Water," Ind. Eng. Chem. Res., 27, 143 (1988).

U.S. EPA, "RCRA Orientational Manual," U.S. EPA Report EPA 530-SW-86-001 (Jan., 1986).

Webley, P. A., and J. W. Tester, "Fundamental Kinetics of Methanol Oxidation in Supercritical Water," Supercritical Fluid Science and Technology, K. P. Johnston and J. M. L. Penninger, eds., ACS Symp. Ser. No. 406 (1989).

Webley, P. A., and J. W. Tester, "Fundamental Kinetics of Methane Oxidation in Supercritical Water," Energy \& Fuels, 5, 411 (1991).

Wightman, T. J., "Studies in Supercritical Wet Air Oxidation," M.S. Thesis, Univ. of California, Berkeley (1981).

Yang, H. H., and C. A. Eckert, "Homogeneous Catalysis in the Oxidation of p-Chlorophenol in Supercritical Water," Ind. Eng. Chem. Res., 27, 2009 (1988).

Yang, H. H., "Homogeneous Catalysis in the Oxidation of p-Chlorophenol in Supercritical Water," PhD Thesis, Univ. of Illinois (1988).

Zimmermann, F. J., "'Wet Air Combustion," Ind. Water. and Wastes, 102 (July-Aug., 1961).

Manuscript received Aug. 29, 1991, and revision received Dec. 27, 1991. 